\title{
Age-Related Disparities in Cancer Screening: Analysis of 2001 Behavioral Risk Factor Surveillance System Data
}

\author{
Anthony F. Jerant, $M D^{1}$ \\ Peter Franks, $M D^{1}$ \\ J. Elizabeth Jackson, $M A^{2}$ \\ Mark P. Doescher, MD, MSPH \\ ${ }^{1}$ Department of Family and Community \\ Medicine, University of California, Davis \\ School of Medicine, Sacramento, Calif \\ ${ }^{2}$ Department of Sociology, \\ University of Washington, Seattle, Wash \\ ${ }^{3}$ Department of Family Medicine, \\ University of Washington \\ School of Medicine, \\ Seattle, Wash

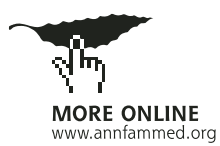

Conflicts of interest: none reported

\section{CORRESPONDING AUTHOR}

Anthony F. Jerant, MD

Department of Family and Community

Medicine

University of California, Davis, School of

Medicine

4860 Y Street, Suite 2300

Sacramento, CA 95817

afjerant@ucdavis.edu

\begin{abstract}
PURPOSE Although few studies have explored age-related health care disparities, some researchers have asserted such disparities uniformly disfavor the elderly and are largely attributable to ageism in the health care system. We compared agerelated patterns of screening for colorectal cancer with those for breast and prostate cancer in persons aged 50 years and older.
\end{abstract}

METHODS We analyzed data for all adults aged 50 years and older $(\mathrm{N}=88,213)$ in the 2001 Behavioral Risk Factor Surveillance System (BRFSS), a nationally representative, telephone-administered survey of personal health behaviors. Main outcome measures were adjusted prevalence by 5 -year age-groups of colorectal cancer screening using fecal occult blood testing, flexible sigmoidoscopy, or colonoscopy for men and women; rates of mammography screening for women; and rates of prostate-specific antigen (PSA) screening for men.

RESULTS After adjustment for race/ethnicity, education level, income, health insurance, and self-rated health, predicted reported colorectal cancer screening (all modalities) increased significantly from when patients reached age 50 years until 70 to 74 years (66.0\%, standard error [SE] $0.8 \%$ ), remained constant until age 80 years, and then declined. The age-related gain in colorectal cancer screening was confined to whites among patients older than 60 years. Reported PSA screening increased until age 75 to 79 years $(79.3 \%$, SE $1.1 \%)$ and then declined, whereas reported mammography screening peaked at age 55 to 59 years (83.3\%, SE $1.2 \%)$ and then declined.

CONCLUSIONS Significant age-related disparities appear to exist for both evidence-based and non-evidence-based cancer-screening interventions. The issue of age-related disparities in cancer screening is complex, with the direction of disparity favoring the elderly for some services yet disfavoring them for others.

Ann Fam Med 2004;2:481-487. DOI: 10.1370/afm.118.

\section{INTRODUCTION}

$\mathrm{D}$ isparities in health care have been extensively documented. ${ }^{1}$ Most research has concerned racial or ethnic and economic disparities, ${ }^{2,3}$ whereas age-related disparities have received less attention. Some evidence does suggest there are age-related disparities disfavoring the elderly in health care access, ${ }_{,}^{4,5}$ provider-patient communication, ${ }_{r}^{6-8}$ and the delivery of certain diagnostic ${ }^{7,9-13}$ and therapeutic ${ }^{5,7,9,10,14-18}$ interventions, and may contribute to poorer treatment outcomes. ${ }^{19}$ Because older adults constitute a large and rapidly growing subpopulation, ${ }^{20}$ age-related disparities in health care merit increased attention.

Although the causes of age-related disparities in care remain unclear, some researchers ${ }^{21-26}$ and advocacy group $\mathrm{s}^{27}$ have invoked the specter of ageism as a pervasive root cause. If so, age-related disparities should uniformly disfavor the elderly. In regard to cancer-screening interventions, 
however, previous studies suggest such disparities might not be the case. Mammography rates do appear to be lower in older than in younger women, ${ }^{11,28-31}$ even though regular mammography in older women could eliminate age-related disparities in breast cancer survival. ${ }^{32}$ By contrast, screening rates for prostate cancer by serum prostate-specific antigen (PSA) testing appears to be higher in men older than 70 years than in those 50 to 65 years old, ${ }^{33,34}$ even though any potential benefit of routine PSA screening (unproved for any age-group) is likely to accrue to men younger than 70 years. ${ }^{35}$ In regard to age-related disparities in colorectal cancer screening, the picture is unclear, with some studies finding increasing age to be associated with increased screening ${ }^{36-39}$ and others finding decreased screening with aging ${ }^{40,41}$ or no differences in screening rates by age. ${ }^{42}$

These conflicting findings bring into question whether ageism is a root cause of age-related disparities in care. The conflicting findings might also reflect limitations of previous studies, particularly sampling problems (eg, selection bias, inadequate size) and inadequate adjustment for confounders. Health status is a particularly important potential confounder, because it has been shown to influence the delivery of some health care services, ${ }^{43,44}$ yet it has not been included in previous analyses of colorectal cancer screening in various age-groups. ${ }^{38,39}$

Thus, we analyzed data from the 2001 Behavioral Risk Factor Surveillance System (BRFSS), a large, nationally representative telephone survey, to address some of the limitations of earlier studies. We sought to determine whether, after adjusting for potential confounders including health status, self-reported rates of completion of evidence-based colorectal cancer screening decrease between the ages of 50 and 80 years, as would be predicted based on ageism bias. We also compared age-related patterns of colorectal cancer screening with those for breast and prostate cancer screening to explore further, in a single data set, agerelated disparities in cancer screening.

\section{METHODS}

The BRFSS, a collaborative project of the Centers for Disease Control and Prevention and US states and territories, is designed to collect uniform, state-specific data on preventive health practices and risk behaviors. The BRFSS telephone-administered questionnaire consists primarily of questions about personal behaviors that increase risk for 1 or more of the 10 leading causes of death in the United States. The BRFSS uses a multistage cluster design based on random-digit dialing to select a representative sample of noninstitutionalized civilian residents aged 18 years or older from each state. Data from each state may be pooled to produce nationally representative estimates, but not all questions are asked by all states each year. For example, in 2001, data on mammography screening were obtained from only 13 states and 2 territories. A detailed description of the survey methods and data is available at http://www.cdc.gov/brfss/index.htm.

We used data from the 2001 BRFSS survey, including sociodemographic information, health status, and information regarding colorectal cancer, prostate cancer, and breast cancer screening. Reported colorectal cancer screening was defined as self-report of having undergone fecal occult blood testing within the previous 2 years, flexible sigmoidoscopy within the previous 5 years, or colonoscopy within the previous 10 years. Reported mammography and PSA screening were each defined as having undergone the test within the previous 2 years. The time frames for determining reported fecal occult blood testing and mammography screening are consistent with the evidence-based recommendations of the US Preventive Services Task Force (USPSTF). ${ }^{28,45}$ The USPSTF found insufficient evidence to recommend optimal screening intervals for flexible sigmoidoscopy and colonoscopy, and a lack of evidence to endorse PSA screening at any interval. Thus, the intervals for flexible sigmoidoscopy and colonoscopy are those recommended by the American Cancer Society. ${ }^{46}$ Finally, a 2 -year interval was chosen for PSA screening to be consistent with the fecal occult blood testing and mammography intervals we used.

We used the SUDAAN statistical software program, Version 8.01 (Research Triangle Institute, Research Triangle Park, NC) in all analyses to account for the complex sampling design and incorporate sample weights that yield nationally representative estimates. We used logistic regression analyses, with reported screening or not for the specific prevention test as the dependent variable. The independent variables were age in years (categorized as 50-54, 55-59, 60-64, 65-69, 70-74, 75-79, or 80 years and older), sex, race/ethnicity (categorized as non-Hispanic white, Hispanic, African American, other race, multiple race, or refused), years of schooling (categorized as <1, 1-8, 9-11, 12, 13-15, 16 years and more, or refused); household income in dollars (categorized as $<\$ 10,000, \$ 10,000-<15,000$, $\$ 15,000-<20,000, \$ 20,000-<25,000, \$ 25,000-<35,000$, $\$ 35,000-<50,000, \$ 50,000-<75,000, \$ 75,000$ or more, unknown, or refused), health insurance status (categorized as any, none, unknown, or refused); and self-rated health (categorized as excellent, very good, good, fair, poor, unknown, or refused). In addition to the main effects, we also examined interactions between agegroup and each of the other independent variables. For 
Table 1. Adjusted Predicted Cancer Screening, by Age-Group

\begin{tabular}{|c|c|c|c|}
\hline $\begin{array}{l}\text { Age- } \\
\text { Group }\end{array}$ & $\begin{array}{l}\text { CRC } \\
\% \text { (SE) }\end{array}$ & $\begin{array}{c}\text { PSA } \\
\% \text { (SE) }\end{array}$ & $\begin{array}{l}\text { Mammography } \\
\% \text { (SE) }\end{array}$ \\
\hline $50-54$ y & $40.3(0.6)$ & $52.4(1.0)$ & $78.6(1.1)$ \\
\hline $55-59$ y & $52.8(0.7)$ & $65.5(1.1)$ & $83.3(1.2)$ \\
\hline $60-64$ y & $58.5(0.8)$ & $70.4(1.2)$ & $80.5(1.3)$ \\
\hline $65-69$ y & $63.1(0.8)$ & $76.0(1.2)$ & $80.7(1.3)$ \\
\hline $70-74$ y & $66.0(0.8)$ & 77.7 (1.0) & $77.9(1.5)$ \\
\hline $75-79$ y & $65.6(0.8)$ & $79.3(1.1)$ & $77.1(1.5)$ \\
\hline$\geq 80 y$ & $60.4(0.9)$ & $71.8(1.4)$ & $65.7(1.8)$ \\
\hline \multicolumn{4}{|c|}{$\begin{array}{l}\text { Note: adjusted for age-group, sex, race/ethnicity, education, income, insurance } \\
\text { status, and self-rated health. }\end{array}$} \\
\hline \multicolumn{4}{|c|}{$\begin{array}{l}\text { CRC }=\text { colorectal cancer screening (fecal occult blood test }<2 \text { years, or flexible } \\
\text { sigmoidoscopy }<5 \text { years and/or colonoscopy }<10 \text { years); PSA = screening } \\
\text { prostate specific antigen screening }<2 \text { years; mammography = mammography } \\
\text { screening }<2 \text { years; SE = standard error. }\end{array}$} \\
\hline
\end{tabular}

ease of interpretation, we report all logistic regression adjusted results as adjusted predicted marginal effects. ${ }^{47}$

Given the large sample size in the BRFSS, we anticipated differences in outcome trends that were similar in direction but only slightly varying in slope would be statistically significant, despite a lack of any clinical relevance to such small differences. Thus, we defined a clinically significant difference in outcome arbitrarily as one in which the parameter effects being compared were different by more than $10 \%$.

\section{RESULTS}

The 2001 BRFSS survey included data for 88,213 adults aged 50 years and older. Descriptive characteristics of the sample are shown in the supplemental table, which

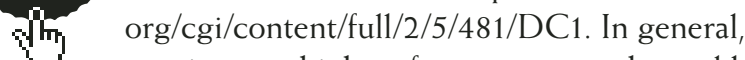
screening was highest for mammography and lowest for colorectal cancer screening. Colorectal cancer screening and PSA screening increased with age until

Table 2. Adjusted Predicted Prostate Cancer Screening, by Age-Group and Self-Rated Health

\begin{tabular}{lccccc}
\hline Age-Group & $\begin{array}{c}\text { Excellent } \\
\% \text { (SE) }\end{array}$ & $\begin{array}{c}\text { Very Good } \\
\% \text { (SE) }\end{array}$ & $\begin{array}{c}\text { Good } \\
\% \text { (SE) }\end{array}$ & $\begin{array}{c}\text { Fair } \\
\% \text { (SE) }\end{array}$ & $\begin{array}{c}\text { Poor } \\
\% \text { (SE) }\end{array}$ \\
\hline $50-54$ y & $51.1(2.0)$ & $49.1(1.7)$ & $53.7(1.7)$ & $55.3(2.8)$ & $58.7(4.0)$ \\
$55-59$ y & $60.6(2.5)$ & $65.9(1.8)$ & $66.4(1.9)$ & $67.7(3.0)$ & $71.9(3.5)$ \\
$60-64$ y & $69.7(2.4)$ & $69.2(2.3)$ & $69.0(2.2)$ & $74.0(2.6)$ & $73.1(3.3)$ \\
$65-69$ y & $69.5(4.3)$ & $79.4(1.8)$ & $75.0(1.8)$ & $78.0(2.5)$ & $78.9(3.0)$ \\
$70-74$ y & $72.9(3.2)$ & $78.7(1.9)$ & $79.7(1.6)$ & $78.3(2.7)$ & $74.0(3.1)$ \\
$75-79$ y & $78.1(3.4)$ & $79.7(2.4)$ & $81.3(1.7)$ & $79.5(2.2)$ & $74.6(3.5)$ \\
$\geq 80$ y & $79.6(3.5)$ & $75.2(2.6)$ & $71.9(2.4)$ & $69.6(3.0)$ & $68.9(4.4)$ \\
\hline Note: adjusted for age-group, sex, race/ethnicity, education, income, insurance status, and self-rated health. \\
SE = standard error.
\end{tabular}

age 70 to 74 years, whereas mammography screening decreased after age 55 to 59 years. Income, education, and insurance were associated with more marked screening gradients than race/ethnicity or self-rated health.

Adjusted predicted marginal cancer-screening percentages by age-group are shown in Table 1 and illustrated in the supplemental figure, which is available online at http://www.annfammed.org/cgi/ content/full/2/5/481/DC1. Colorectal cancer screening increased until age 70 to 74 years and declined after the age of 80 years. Similar age trends were observed for fecal occult blood testing alone (the dominant colorectal screening modality), when a 1 -year interval was used to define screening, and in an analysis confined to those with health insurance (data not shown). PSA screening increased until age 75 to 79 years, and then declined. Mammography screening peaked at age 55 to 59 years and then declined.

For colorectal cancer screening, interactions between age-group and self-rated health and health plan were statistically significant $(P=.01$ and $P=.02$, respectively) but not clinically meaningful, and interactions between age-group and sex and education were neither statistically nor clinically significant. For PSA screening, the interaction between age-group and education was statistically $(P=.01)$ but not clinically significant, and the interaction between age-group and health insurance was neither clinically nor statistically significant. For PSA screening, the interaction between age-group and self-rated health was statistically and clinically significant $(P<.001)$, with those lower in self-reported health reporting higher levels of screening at younger ages (Table 2).

Interactions between age-group and race/ethnicity for each of the screening procedures displayed are shown in Table 3. This interaction was statistically and clinically significant for colorectal screening and PSA screening. For colorectal cancer screening, the age-related gain in screening for those older than 60 years was confined to whites. For both

PSA and mammography screening, African Americans and Hispanics had higher screening rates at younger ages than did whites.

\section{DISCUSSION}

By showing complex interactions between age and cancer screening, our findings provide evidence to rebut the notion that age-related disparities in care uniformly stem from ageism and disfavor the elderly. 


\begin{tabular}{|c|c|c|c|c|c|c|}
\hline Age-Group & $\begin{array}{l}\text { White } \\
\% \text { (SE) }\end{array}$ & $\begin{array}{c}\text { African American } \\
\% \text { (SE) }\end{array}$ & $\begin{array}{c}\text { Other Race } \\
\% \text { (SE) }\end{array}$ & $\begin{array}{c}\text { Multi-Race } \\
\% \text { (SE) }\end{array}$ & $\begin{array}{c}\text { Hispanic } \\
\% \text { (SE) }\end{array}$ & $\begin{array}{c}\text { Refused } \\
\% \text { (SE) }\end{array}$ \\
\hline \multicolumn{7}{|c|}{ Colorectal cancer screening } \\
\hline $50-54$ y & $40.4(0.6)$ & $43.2(2.2)$ & $34.2(3.9)$ & $38.1(4.6)$ & $36.0(2.5)$ & $45.4(6.2)$ \\
\hline $55-59$ y & $52.6(0.7)$ & $63.1(2.5)$ & $39.1(4.6)$ & $64.1(4.6)$ & $48.0(3.5)$ & $51.5(6.8)$ \\
\hline $60-64$ y & $60.5(0.8)$ & $60.8(3.0)$ & $43.9(4.8)$ & $55.2(5.9)$ & $44.6(3.9)$ & $63.7(6.5)$ \\
\hline $65-69$ y & $65.2(0.8)$ & $62.3(2.8)$ & $45.6(6.4)$ & $56.8(5.9)$ & $52.2(3.8)$ & $66.3(5.8)$ \\
\hline $70-74$ y & $68.4(0.8)$ & $59.2(3.3)$ & $56.5(8.1)$ & $62.1(6.6)$ & $54.2(4.0)$ & $44.2(7.0)$ \\
\hline $75-79 y$ & $67.0(0.9)$ & $60.1(4.0)$ & $53.8(8.0)$ & $66.3(6.3)$ & $66.1(4.7)$ & $44.6(7.8)$ \\
\hline$\geq 80$ y & $62.3(0.9)$ & $52.1(4.4)$ & $41.5(6.6)$ & $67.2(7.7)$ & $54.9(6.5)$ & $50.1(6.1)$ \\
\hline \multicolumn{7}{|c|}{ Prostate-specific antigen screening } \\
\hline $50-54$ y & $50.5(1.0)$ & $67.8(3.1)$ & $43.2(5.6)$ & $44.7(6.5)$ & $58.2(3.9)$ & $61.0(8.9)$ \\
\hline $55-59$ y & $64.5(1.1)$ & $77.3(3.2)$ & $49.3(7.4)$ & $63.5(7.3)$ & $70.9(4.5)$ & $68.2(7.3)$ \\
\hline $60-64$ y & $71.6(1.1)$ & $76.7(4.1)$ & $60.7(6.0)$ & $63.7(7.9)$ & $62.2(6.3)$ & $68.0(9.6)$ \\
\hline $65-69 y$ & $77.5(1.0)$ & $75.3(4.1)$ & $54.6(9.7)$ & $66.1(7.9)$ & $74.4(5.5)$ & $78.4(6.1)$ \\
\hline $70-74$ y & $78.9(1.0)$ & $72.8(4.6)$ & $67.1(6.7)$ & $77.6(7.8)$ & $72.0(7.0)$ & $79.0(7.0)$ \\
\hline $75-79 y$ & $80.3(1.1)$ & $78.9(4.4)$ & $79.3(7.3)$ & $75.0(9.2)$ & $66.2(6.7)$ & $50.610 .8)$ \\
\hline$\geq 80 y$ & $71.9(1.5)$ & $70.6(8.2)$ & $68.4(8.3)$ & $74.3(9.2)$ & $76.2(6.6)$ & $58.0(11.2)$ \\
\hline \multicolumn{7}{|c|}{ Mammography screening } \\
\hline $50-54 y$ & $77.5(1.4)$ & $85.3(2.3)$ & $67.7(6.0)$ & $75.2(7.6)$ & $88.6(3.1)$ & $59.1(20.2)$ \\
\hline $55-59$ y & $82.4(1.4)$ & $90.7(2.2)$ & $81.4(5.7)$ & $75.8(6.6)$ & $83.2(5.4)$ & $91.5(9.5)$ \\
\hline $60-64$ y & $78.8(1.5)$ & $87.0(3.5)$ & $84.7(4.7)$ & $91.7(4.7)$ & $83.5(4.9)$ & $93.2(4.4)$ \\
\hline $65-69 y$ & $79.8(1.5)$ & $87.3(3.0)$ & $84.1(6.2)$ & $86.7(5.8)$ & $79.9(7.5)$ & $64.1(20.8)$ \\
\hline $70-74$ y & $77.6(1.6)$ & $83.7(4.1)$ & $75.0(6.0)$ & $54.7(8.3)$ & $74.5(8.3)$ & $82.3(10.8)$ \\
\hline $75-79 y$ & $75.8(1.7)$ & $89.0(3.0)$ & $71.3(7.8)$ & $53.8(8.8)$ & $81.4(6.7)$ & $88.9(7.7)$ \\
\hline$\geq 80 \mathrm{y}$ & $66.0(1.9)$ & $60.5(8.1)$ & $58.0(8.8)$ & $53.9(1.9)$ & $69.7(9.3)$ & $69.8(12.8)$ \\
\hline
\end{tabular}

We compared colorectal screening with mammography screening because both are evidence based and should be periodically offered (eg, 5 years for mammography ${ }^{28,48}$ and 10 years for colorectal cancer screening $^{45}$ ) to all adults with reasonable life expectancy. If such services were being optimally delivered, screening rates should be relatively high through age 70 to 75 years and gradually decline thereafter. We further compared colorectal screening with PSA screening because the latter maneuver is not firmly evidence based, and even PSA advocates have suggested its potential value is likely to be low beyond the age of 70 years. Thus, if PSA screening were being optimally deployed, PSA screening should be relatively low at any age compared with colorectal cancer screening.

Our findings contrasted sharply with these expectations. We found colorectal cancer screening, after adjustment for potential confounders including health status, was relatively low at age 50 years, peaked at 70 to 74 years, and remained high until the age of 80 years. This finding is counterintuitive given that the peak age of incidence for adenomatous polyps is 55 to 65 years. ${ }^{49}$ Furthermore, the disparity cannot be explained by systematic ageism bias, because it actually reflects relative underuse of screening by younger adults. Increased colorectal cancer screening with age might instead reflect appropriate recognition by older persons of their high absolute risk of dying from colorectal cancer ${ }^{49}$ or that they have been educated about and offered colorectal cancer screening repeatedly over a period of years.

Findings of previous studies regarding age effects in colorectal cancer screening were conflicting. ${ }^{36-42}$ We hypothesized that failure to uniformly account for potential confounders, such as health status, ${ }^{43,44}$ might help to explain these conflicting findings. We found no clinically significant interactions, however, between age and most other characteristics, including self-reported health. We did find a clinically significant interaction between age-group and race/ethnicity, with age-related gains in colorectal cancer screening being limited to whites aged 60 years and older. This finding is consistent with earlier research regarding race- and ethnicityrelated health care disparities. ${ }^{2}$ It suggests that greater progress has been achieved in reducing race and ethnicity disparities in younger persons than in older persons. 
Rather than being attributable to confounding problems, the varying findings of earlier studies probably stemmed from problems with study samples and other analytic approaches. For example, a study using Medicare claims data found no significant differences in colorectal cancer screening between the ages of 65 and 80 years, ${ }^{42}$ but data were not available for adults younger than 65 years, a group we found that had relatively low screening rates. Likewise, of 2 previous studies that found colorectal cancer screening decreased with age, one ${ }^{41}$ involved mostly male, white retired automobile company employees, a poorly representative sample. The other, which used data from the 1998 National Health Interview Survey, ${ }^{40}$ grouped subjects older than 65 years into a single category, precluding detection of age-group-related trends in this range.

Regarding PSA screening, our findings also ran counter to expectations based on plausibly optimal deployment of screening. We found screening increased steadily from the age of 50 years through 75 to 79 years, a finding consistent with those of previous studies. ${ }^{33,34}$ The benefit of PSA screening at any age is unclear, but it is particularly unlikely to benefit men aged 70 years and older. ${ }^{35}$ In this context, our finding suggests relative overuse of PSA screening, particularly in older men, an example of an age-related disparity that disfavors the elderly. Ageist health care provider perceptions (eg, prostate cancer is an older man's disease) and practices (eg, failure to adequately inform older men of the potential drawbacks of PSA screening along with theoretical benefits ${ }^{50}$ ) could be invoked to explain this finding. Equally plausible explanations involve factors unrelated to ageism, such as patient or provider lack of understanding of the lead time required to benefit from screening.

Finally, our finding that mammography screening peaked in women aged 55 to 59 years and then declined steadily (disparity disfavors the elderly) was also unexpected based on an optimal deployment rationale but was consistent with previous research regarding actual deployment. ${ }^{11,28-32}$ Inaccurate provider perceptions regarding the receptiveness of older women to mammography, a form of ageism bias, has been invoked to help explain this disparity by some, who cite evidence that screening mammography should be discussed with all women with an estimated life expectancy of more than 5 years regardless of age. ${ }^{28,48}$ Understandable physician uncertainty regarding the benefit of mammography in older women might also play a role, however, because screening trials and prominent screening guidelines have largely excluded women older than 70 years. ${ }^{51}$ The higher absolute prevalence of mammography screening in younger persons compared with colorectal screening and PSA screening was likely due to mammography having been an established element of preventive care for a longer time. In addition, mammography screening often begins when women reach 40 years, ${ }^{52,53}$ entailing earlier patient education regarding and habituation to undergoing mammography than for colorectal screening and PSA screening.

There are several limitations of this report. The BRFSS is based upon self-report, and it is difficult to identify reliably whether a particular intervention was conducted for screening or diagnostic purposes. Thus, part of the observed increase in colorectal cancer screening with increasing age could be attributable to greater diagnostic use of these tests. Such a phenomenon could arise as a result of a more frequent occurrence of symptoms (eg, rectal bleeding) with aging and, probably more importantly, as a consequence of increased use of screening fecal occult blood testing with aging (eg, follow-up endoscopy to evaluate screening tests that are positive for fecal occult blood) Another limitation of our study is the possibility of unmeasured confounding accounting for the observed disparities. For example, it is possible that evolving changes in cancer-screening practice guidelines and Medicare coverage for cancer-screening services might have influenced our results to a small extent. Further biases could have occurred, because the BRFSS is a telephone-based survey, and persons without telephones might be less likely to obtain screening procedures. Also, younger respondents (eg, those aged 50 to 51 years) in the BRFSS had just entered the eligible age range for colorectal screening and PSA screening. These younger respondents who were interested in undergoing screening might not have had enough time to actually do so and would be classified as nonadherent to screening recommendations, somewhat artificially reducing screening rates for the 50 - to 55 -year-old age-group. The impact of this recent eligibility effect on our results was likely small, however. A final limitation is that the mammography questions in the 2001 BRFSS were asked in only 13 states and 2 territories, so that screening mammography prevalence data might not be fully representative of that for the US population as a whole. It is doubtful, however, that these limitations could account for the relative differences in age-related prevalence among the 3 screening procedures.

\section{CONCLUSIONS}

Our findings emphasize that the issue of age-related disparities in health care is complex, with the nature and direction of such disparities varying with the particular aspect of care being considered. Significant 
age-related disparities appear to exist in regard to 2 evidence-based cancer-screening interventions, colorectal screening and mammography screening, and 1 nonevidence-based cancer-screening intervention, PSA testing. The age-related disparity in colorectal cancer screening appears to favor the elderly and disfavor younger adults in terms of public health care implications ${ }^{54}$; however, the disparities in PSA (probable overuse) and mammography (probable underuse) screening appear to be in a direction unfavorable to the elderly. Generalization regarding a systematic ageism bias and a priori prediction of the magnitude and direction of agerelated health care disparities does not appear possible. In the context of these observations, along with the substantial impact that age-related disparities in care could have on our health care system with the ongoing growth of the population of adults aged 65 years and older, increased research attention in this area appears warranted.

\section{To read or post commentaries in response to this article, see it} online at http://www.annfammed.org/cgi/content/full/2/5/481 .

Key words: Health services accessibility; health services for the aged; health care surveys; preventive health services; mass screening

Submitted August 3, 2003; submitted, revised, December 1, 2003; accepted December 18, 2003

\section{References}

1. Committee on Quality Health Care in America. Institute of Medicine. Crossing the Quality Chasm: A New Health System for the 21st Century. Washington, DC: National Academy Press; 2001:364.

2. Fiscella K, Franks P, Gold MR, Clancy CM. Inequality in quality: addressing socioeconomic, racial, and ethnic disparities in health care. JAMA. 2000;283:2579-2584.

3. Board on Health Sciences Policy. Institute of Medicine. Unequal Treatment: Confronting Racial and Ethnic Disparities in Health Care. Washington, DC: National Academy Press; 2002:782.

4. Gurwitz JH, Goldberg RJ, Malmgren JA, et al. Hospital transfer of patients with acute myocardial infarction: the effects of age, race, and insurance type. Am J Med. 2002;112:528-534.

5. Bowling A, Bond M, McKee D, et al. Equity in access to exercise tolerance testing, coronary angiography, and coronary artery bypass grafting by age, sex and clinical indications. Heart. 2001:85:680-686

6. Silliman RA, Troyan SL, Guadagnoli E, Kaplan SH, Greenfield S. The impact of age, marital status, and physician-patient interactions on the care of older women with breast carcinoma. Cancer. 1997;80:1326-1334

7. Hajjar I, Miller K, Hirth V. Age-related bias in the management of hypertension: a national survey of physicians' opinions on hypertension in elderly adults. J Gerontol A Biol Sci Med Sci. 2002;57:M487M491.

8. Madan AK, Aliabadi-Wahle S, Beech DJ. Age bias: a cause of underutilization of breast conservation treatment. J Cancer Educ. $2001 ; 16: 29-32$

9. Majeed FA, Cook DG. Age and sex differences in the management of ischaemic heart disease. Public Health. 1996;110:7-12.
10. Bearden D, Allman R, McDonald R, Miller S, Pressel S, Petrovitch H. Age, race, and gender variation in the utilization of coronary artery bypass surgery and angioplasty in SHEP. SHEP Cooperative Research Group. Systolic Hypertension in the Elderly Program. J Am Geriatr Soc. 1994;42:1143-1149.

11. Jazieh AR, Buncher CR. Racial and age-related disparities in obtaining screening mammography: results of a statewide database. South Med J. 2002;95:1145-1148

12. Cooper GS, Yuan Z, Chak A, Rimm AA. Geographic and patient variation among Medicare beneficiaries in the use of follow-up testing after surgery for nonmetastatic colorectal carcinoma. Cancer. 1999;85:2124-2131.

13. Hillner BE, Penberthy L, Desch CE, McDonald MK, Smith TJ, Retchin SM. Variation in staging and treatment of local and regional breast cancer in the elderly. Breast Cancer Res Treat. 1996;40:75-86.

14. Uncapher $\mathrm{H}$, Arean PA. Physicians are less willing to treat suicidal ideation in older patients. J Am Geriatr Soc. 2000;48:188-192.

15. Whittle J, Wickenheiser $\mathrm{L}$, Venditti LN. Is warfarin underused in the treatment of elderly persons with atrial fibrillation? Arch Intern Med. 1997:157:441-445.

16. McCrory DC, Matchar DB, Samsa G, Sanders LL, Pritchett EL. Physician attitudes about anticoagulation for nonvalvular atrial fibrillation in the elderly. Arch Intern Med. 1995;155:277-281.

17. Jazieh AR, Kyasa MJ, Sethuraman G, Howington J. Disparities in surgical resection of early-stage non-small cell lung cancer. J Thorac Cardiovasc Surg. 2002;123:1173-1176.

18. VanEenwyk J, Campo JS, Ossiander EM. Socioeconomic and demographic disparities in treatment for carcinomas of the colon and rectum. Cancer. 2002;95:39-46.

19. American Cancer Society. Breast cancer facts and figures: 20012002. Available at: http://www.cancer.org/docroot/STT/content/ STT_1x_Breast_Cancer_Facts_and_Figures_2001-2002.asp. Accessed February 6, 2003.

20. U.S. Census Bureau home page. Available at: http://www.census.gov. Accessed January 16, 2003

21. Ory M, Kinney Hoffman M, Hawkins M, Sanner B, Mockenhaupt R. Challenging aging stereotypes: strategies for creating a more active society. Am J Prev Med. 2003;25:164-171.

22. Treating the elderly badly. U.S. News and World Report. August 11, 2003. Available at: http://www.usnews.com/usnews/nycu/health/ articles/030811/11 cancer.htm. Accessed November 20, 2003.

23. Langer CJ. Elderly patients with lung cancer: biases and evidence. Curr Treat Options Oncol. 2002;3:85-102.

24. Mahoney T, Kuo YH, Topilow A, Davis JM. Stage III colon cancers: why adjuvant chemotherapy is not offered to elderly patients. Arch Surg. 2000;135:182-185.

25. Greenfield S, Blanco DM, Elashoff RM, Ganz PA. Patterns of care related to age of breast cancer patients. JAMA. 1987;257:2766-2770.

26. Bennett CL, Greenfield S, Aronow H, Ganz P, Vogelzang NJ, Elashoff RM. Patterns of care related to age of men with prostate cancer. Cancer. 1991:67:2633-2641.

27. Alliance for Aging Research. Ageism: How Healthcare Fails the Elderly. Washington, DC: Alliance for Aging Research;2003:17.

28. Caplan LS. To screen or not to screen: the issue of breast cancer screening in older women. Public Health Rev. 2001;29:231-240.

29. Horton Taylor D, McPherson K, Parbhoo S, Perry N. Response of women aged 65-74 to invitation for screening for breast cancer by mammography: a pilot study in London, UK. J Epidemiol Community Health. 1996;50:77-80

30. Finison KS, Wellins CA, Wennberg DE, Lucas FL. Screening mammography rates by specialty of the usual care physician. Eff Clin Pract. 1999;2:120-125. 
31. Maxwell CJ, Bancej CM, Snider J. Predictors of mammography use among Canadian women aged 50-69: findings from the 1996/97 National Population Health Survey. CMAJ. 2001;164:329-334.

32. Randolph WM, Goodwin JS, Manhken JD, Freeman JL. Regular mammography use is associated with elimination of age-related disparities in size and stage of breast cancer at diagnosis. Ann Intern Med. 2002;137:783-790.

33. Lemon S, Zapka J, Puleo E, Luckmann R, Chasan-Taber L. Colorectal cancer screening participation: comparisons with mammography and prostate-specific antigen screening. Am J Public Health. 2001:91:1264-1272.

34. Collins MM, Stafford RS, Barry MJ. Age-specific patterns of prostatespecific antigen testing among primary care physician visits. J Fam Pract. 2000:49:169-172.

35. U.S. Preventive Services Task Force. Screening for prostate cancer: recommendations and rationale. Available at: http://www.ahrq. gov/clinic/3rduspstf/prostatescr/prostaterr.htm. Accessed February 10 2003.

36. Walsh JM, Posner SF, Perez-Stable EJ. Colon cancer screening in the ambulatory setting. Prev Med. 2002;35:209-218.

37. Zapka JG, Puleo E, Vickers-Lahti M, Luckmann R. Healthcare system factors and colorectal cancer screening. Am J Prev Med. 2002;23:2835.

38. Seeff LC, Shapiro JA, Nadel MR. Are we doing enough to screen for colorectal cancer? Findings from the 1999 Behavioral Risk Factor Surveillance System. J Fam Pract. 2002;51:761-766.

39. Sirovich BE, Schwartz LM, Woloshin S. Screening men for prostate and colorectal cancer in the United States: does practice reflect the evidence? JAMA. 2003;289:1414-1420.

40. Breen N, Wagener DK, Brown ML, Davis WW, Ballard-Barbash R. Progress in cancer screening over a decade: results of cancer screening from the 1987, 1992, and 1998 National Health Interview Surveys. J Natl Cancer Inst. 2001;93:1704-1713.

41. Musich S, Ignaczak A, McDonald T, Hirschland D, Edington DW. Self-reported utilization of preventive health services by retired employees age 65 and older. J Am Geriatr Soc. 2001;49:1665-1672.
42. Ko CW, Kreuter W, Baldwin LM. Effect of Medicare coverage on use of invasive colorectal cancer screening tests. Arch Intern Med. 2002;162:2581-2586.

43. Chao A, Paganini-Hill A, Ross RK, Henderson BE. Use of preventive care by the elderly. Prevent Med. 1987;16:710-722.

44. Schoen RE, Marcus M, Braham RL. Factors associated with the use of screening mammography in a primary care setting. J Community Health. 1994;19:239-252

45. U.S. Preventive Services Task Force. Screening for colorectal cancer: recommendations and rationale. Ann Intern Med. 2002;137:129-131.

46. Smith RA, Cokkinides V, Eyre HJ. American Cancer Society guidelines for the early detection of cancer, 2003. CA Cancer J Clin. 2003;53:27-43

47. Graubard $\mathrm{Bl}$, Korn EL. Predictive margins with survey data. Biometrics. 1999:55:652-659.

48. American Geriatrics Society Clinical Practice Committee position statement. Breast cancer screening in older women. Available at: http://www.americangeriatrics.org/products/positionpapers/brstencr. shtml. Accessed January 17, 2003

49. Scholefield JH. Screening for colorectal cancer. Br Med Bull. 2002;64:75-80.

50. Wolf AM, Schorling JB. Preferences of elderly men for prostate-specific antigen screening and the impact of informed consent. J Gerontol A Biol Sci Med Sci. 998;53:M195-M200.

51. McPherson CP, Swenson KK, Lee MW. The effects of mammographic detection and comorbidity on the survival of older women with breast cancer. J Am Geriatr Soc. 2002;50:1061-1068.

52. Screening for breast cancer: recommendations and rationale. Ann Intern Med. 2002:137:344-346.

53. Smith RA, Mettlin CJ, Davis KJ, Eyre H. American Cancer Society guidelines for the early detection of cancer. CA Cancer J Clin. 2000;50:34-49.

54. Office of Disease Prevention and Health Promotion, U.S. Department of Health and Human Services. Healthy People 2010. Available at: http://www.healthypeople.gov. Accessed January 17, 2003. 